\title{
Quercetin Improves the Apoptotic Index and Oxidative Stress in Post-Thaw Dog Sperm
}

\section{Seonggyu Bang}

Chungnam National University

\section{Ahmad Yar Qamar}

Chungnam National University

\section{Bereket Molla Tanga}

Chungnam National University

\section{Xun Fang}

Chungnam National University

\section{Gyeonghwan Seong}

Chungnam National University

Abdelbagi Hamad Talha Nabeel

Jeonbuk National University

Il-Jeoung Yu

Jeonbuk National University

Islam M. Saadeldin

Chungnam National University

JongKi Cho ( $\square$ cjki@cnu.ac.kr)

Chungnam National University

\section{Research Article}

Keywords: dog, oxidative stress, post-thaw, quercetin, sperm

Posted Date: September 14th, 2021

DOl: https://doi.org/10.21203/rs.3.rs-863422/v1

License: @ (i) This work is licensed under a Creative Commons Attribution 4.0 International License. Read Full License

Version of Record: A version of this preprint was published at Environmental Science and Pollution Research on November 13th, 2021. See the published version at https://doi.org/10.1007/s11356-021-17421-6. 


\section{Abstract}

This study was conducted to investigate if quercetin (QRN) may ameliorate apoptosis and oxidative stress in post-thaw dog sperm. Herein, we evaluated the post-thaw apoptosis and oxidative stress after treatment with QRN (control, 25, 50, and $100 \mu \mathrm{M}$ ) in freezing of dog semen. The oxidative stress index was significantly affected $(p<0.05)$ between the various concentrations of QRN and the control $(17.56 \pm 1.02,7.54 \pm 0.48,5.66$ \pm 0.80 , and $10.41 \pm 0.69$ ), respectively. The apoptosis index was $9.1 \pm 1.34,6.66 \pm 0.58,6.77 \pm 0.66$, and $5.38 \pm$ 0.86 in the control, and 25,50 , and $100 \mu \mathrm{M} Q R N$ treatment groups, respectively $(p<0.05)$. The effects of ameliorated cryo-induced damage by QRN on post-thaw sperm quality were also observed through improved structural and functional tests. Sperm treated with $50 \mu \mathrm{M}$ QRN showed significantly higher motility (51.8 \pm $2.1 \%$ vs. $43.1 \pm 1.4 \%, \mathrm{P}<0.05)$, survival rates $(46.9 \pm 0.7 \%$ vs. $43.9 \pm 0.4 \%, \mathrm{P}<0.05)$, and mucus penetration than control group, respectively. Results demonstrate that supplementing freezing buffer with $50 \mu \mathrm{M} Q R N$ reduced oxidative damage and improved the quality of post-thaw dog sperm.

\section{Introduction}

Artificial insemination using frozen dog semen is associated with a sluggish progress compared with that of other animal species (England 1993). Identifying the best cryoprotectant for preventing cryodamage-induced molecular toxicity in dog sperm post-thaw is a focus for several research groups, including our group (Farstad 2009, Qamar et al. 2020). Reactive oxygen species (ROS) are resulted from physiological cellular metabolic processes, which pushes the cells to early aging and apoptosis (Redza-Dutordoir \&Averill-Bates 2016). Organisms have diverse and complex systems to balance and maintain harmless intracellular ROS levels to protect phospholipids, proteins, and DNA from the adverse effects of ROS (Schieber \&Chandel 2014).

In sperm cryopreservation, due to discarding the seminal plasma, sperms lack essential antioxidants that defeat ROS (Kashou et al. 2013), and further oxidative stress develops, which potentiates cryo-induced stress, damage, and subsequent apoptosis (Fraser et al. 2011, Iwasaki \&Gagnon 1992, Papas et al. 2019). The cryopreservation of cells promotes the oxidation of phospholipids in the cell membrane, increases intracellular ROS, and thus leads to DNA fragmentation and cell membrane damage (El-Said et al. 2014, Su et al. 2019). This, in turn, compromises the fertility quality of post-thaw sperm. Therefore, supplementation with antioxidants has been applied to prevent ROS, reduce its effect on cell components, and retain the fertility quality of sperm, such as motility and viability (Snezhkina et al. 2019). These antioxidants reduce ROS generation and/or eliminate the generated ROS in the cells of an organism (Liu et al. 2021). Antioxidants play important roles as oxidation inhibitors by scavenging free radicals (Barciszewski et al. 2000). Antioxidantsupplemented sperm showed reduced lipid peroxidation, enabling the plasma membrane to maintain normal physiological and metabolic activity, ultimately resulting in enhanced viability (Alvarez \&Storey 1989). Several studies reported the useful effects of antioxidants during semen freezing to minimize the adverse impacts of ROS on spermatozoa has been reported, thereby improving post-thaw quality (Bansal \&Bilaspuri 2010, Malo et al. 2010, Qamar et al. 2020, Setyawan et al. 2016, Yoshimoto et al. 2008). However, finding an appropriate species-specific antioxidant is the target of several research groups to alleviate the cryodamage and maintaining functional integrity of spermatozoa during freezing process (Bansal \&Bilaspuri 2010). For instance, a-Linoleic acid was shown to suppress ROS generation by stabilizing the plasma membrane during the cryopreservation of boar sperm (Qamar et al. 2020). In canine species, several antioxidants and ROS 
scavenger supplements were used for sperm cryopreservation, including rosemary and spermine (Setyawan et al. 2016, Vieira et al. 2018).

Interestingly, externalization and translocation of phosphatidylserine (PS) from the inner leaflet of sperm membranes to the external leaflet considers as an early marker of apoptosis in spermatozoa (Martin et al. 2005, Shiratsuchi et al. 1997). ROS production is significantly related to the activity of anti-apoptotic Bcl2 and pro-apoptotic BAX proteins (Setyawan et al. 2016). DNA integrity is also a concern, as cryopreservation alters the properties of the mitochondrial membrane and increases the generation of free radicals that affect DNA oxidation and lead to single- and double-strand DNA breaks (Ahmed \&Lingner 2020, Ricci et al. 2002).

Quercetin is a flavonol from the flavonoid group of polyphenols found in many fruits, vegetables, and seeds (Formica \&Regelson 1995). Quercetin prevents peroxidation in organisms, displays anti-cancer, antibacterial, and anti-inflammatory effects, reduces nanoparticles toxicity, and improves oocyte in vitro maturation (Ezzati et al. 2020, Han et al. 2021, Hussein et al. 2016, Kang et al. 2016, Moodi et al. 2021). Quercetin can scavenge ROS and hydroxyl radicals (Kim et al. 2020), and can modulate the mitochondrial membrane potential by restoring ATP levels, blocking caspase-3, and minimizing DNA unpacking (Bali et al. 2014). Electron transport chain and cytochrome $c$ were reported to be the molecular targets of quercetin, preventing $\mathrm{H}_{2} \mathrm{O}_{2}$ production and protecting mitochondrial function and integrity (Carrasco-Pozo et al. 2012, Tanga et al. 2021).

Quercetin supplementation in human sperm caused significant improvements in frozen/thawed spermatozoa motility, viability, and DNA integrity (Zribi et al. 2012). In human and bovine, quercetin was demonstrated to be a ROS scavenging, reduce $\mathrm{H}_{2} \mathrm{O}_{2}$ level, and metal-chelating agent that prevented the alterations caused by ROS such as DNA fragmentation and preserved sperm function (Azadi et al. 2017, Diao et al. 2019, Tvrdá et al. 2016). At the molecular level, quercetin acts by reducing ROS levels inside the cell by scavenging free radical species (Russo et al. 2012). In other studies, quercetin was found to inhibit phosphorylation and prevent apoptosis (Moon \&Morris 2007). Quercetin can be a pro-oxidative in the long-term uses (Ashida et al. 2000) and its action is dose-dependent, particularly in the cell culture conditions (Fukuda \&Ashida 2008). Therefore, determining the optimum concentration and conditions for the use of quercetin is vital for its application.

We hypothesized that supplementing the freezing extender with quercetin could preserve sperm fertility in dogs by reducing free radical production, oxidative stress, and subsequent apoptosis. Therefore, we examined the impacts of supplementing various concentrations of quercetin on ROS, OS, and sperm apoptosis. Furthermore, we carried out some structural and functional tests on sperm to assess the indicators of fertility quality.

\section{Materials And Methods}

\subsection{Animals and ethics}

Four healthy beagles (age, 2-4 years old; weight, 8-12 kg) were used in the current study. Formulated food and water were available ad libitum to the beagles and were maintained in a comfortable facility and isolated from external stresses. All experimental procedures and animal care were approved by Chungnam National University (approval no. 202006A-CNU-103).

\subsection{Semen collection and freezing}


Semen was collected two times per week using digital manipulation for a total of eight times. The pooled semen was washed, diluted, and analyzed using a computer-aided sperm analysis software (MICROTOPIC CASA System; SCA class analyzer, Josep Tarradellas, Barcelona, Spain). Samples of more than $100 \times 10^{6}$ sperms $/ \mathrm{mL}, 70 \%$ motility, and $80 \%$ viability were selected, pooled and processed. Cell debris was discarded after centrifugation at $100 \times \mathrm{g}$ for $1 \mathrm{~min}\left(\right.$ at $\left.25^{\circ} \mathrm{C}\right)$, then the supernatant was used. The supernatant was mixed buffer $1(1 \mathrm{v} / 1 \mathrm{v})$ and centrifuged at $700 \times \mathrm{g}$ for $2 \mathrm{~min}$ at $25^{\circ} \mathrm{C}$ to collect the pellets (Bang et al. 2021). Sperm

pellet was resuspended in buffer 1 to attain a $200 \times 10^{6} \mathrm{sperm} / \mathrm{mL}$, and was then adjusted to $100 \times 10^{6}$ sperms $/ \mathrm{mL}$ by adding a freezing extender that contained 0 (control), 25,50, or $100 \mu \mathrm{M}$ quercetin. After dilution, the samples were loaded into $0.5 \mathrm{~mL}$ straws (Minitube, Tiefenbach, Germany) and cooled for 45-60 min at $4^{\circ} \mathrm{C}$. Sperm freezing was performed through keeping the straws about $2-4 \mathrm{~cm}$ above the level of liquid nitrogen $\left(\mathrm{LN}_{2}\right)$ for $10-15 \mathrm{~min}$. The frozen straws were stored in an $\mathrm{LN}_{2}$ container $\left(-196^{\circ} \mathrm{C}\right)$. For thawing, straws were maintained at $37^{\circ} \mathrm{C}$ for $30 \mathrm{~s}$ and semen was sequentially diluted with buffer 1 for further evaluation within 5-10 min after thawing.

\subsection{Computer-aided sperm analysis (CASA) of thawed sperms}

Five $\mu \mathrm{L}$ of post-thaw sperm samples were transferred onto a clean glass slide to assess the motility and motion characteristics using a CASA imaging system. For the analysis, five fields of more than 200 sperms for each semen sample were monitored for $1 \mathrm{~s}$ at $25 \mathrm{~Hz}$. The proportions of total and progressive motility were analyzed. The recorded motion characteristics were curvilinear velocity (VCL), average path velocity (VAP), straight-line velocity (VSL), straightness, linearity, and amplitude of lateral head displacement (ALH).

\subsection{Flow cytometric analysis}

Flow cytometry analysis was performed through BD Accuri' $\mathrm{T}$ ' 6 plus (Becton Dickinson, BD Biosciences, Franklin Lakes, NJ, USA). The flow cytometer was fitted with blue (488-nm, solid state, $20 \mathrm{~mW}$ ) and diode red $(640 \mathrm{~nm}, 14.7 \mathrm{~mW})$ excitation lasers. The fluorescent probes used in this experiment were 2,7-

dichlorodihydrofluorescein diacetate (H2DCFDA) (Molecular Probes, Inc., OR, USA), and annexin V-FITC (Apoptosis detection kit I (BD Biosciences), and propidium iodide (Malo et al.) were excited using a $488 \mathrm{~nm}$ blue-solid state laser. Live spermatozoa stained with H2DCFDA and annexin V were detected using a filter detector $533 / 30 \mathrm{BP}$ (wavelength range $511-543 \mathrm{~nm}$ ). The signal from dead sperm stained with propidium iodide was detected using a filter detector 586/42 BP (wavelength range 565-607 nm). The flow rate of the flow cytometer was medium ( $35 \mu \mathrm{L} / \mathrm{min}, 16 \mu \mathrm{m}$ core). Sperm populations were divided into regions and quadrants. The data were analyzed using BD Accuri"' CFlow software.

\subsection{Level of ROS and PS translocation index}

ROS levels were assessed according to the experimental protocol of Guthrie and Welch (Guthrie \&Welch 2010). Briefly, ROS in the sperm was detected using H2DCFDA. The level of ROS was evaluated by measuring the fluorescence intensity of H2DCFDA in the live sperm population. All samples were analyzed to derive their fluorescence signals using a BD Accuri" C6 Plus flow cytometer. The data are expressed as the percentage of ROS molecules measured in live sperm. The PS translocation status was assessed through the annexin V-FITC detection Kit. Briefly, spermatozoa were pelleted twice using PBS at $300 \times \mathrm{g}$ for $5 \mathrm{~min}$, and then diluted in $1 \mathrm{~mL}$ of $1 \times$ annexin buffer $\left(5 \times 10^{6} \mathrm{sperm} / \mathrm{mL}\right)$. From this suspension, $100 \mu \mathrm{L}$ was collected in new $1.5 \mathrm{~mL}$ tubes, 
and mixed with $5 \mu \mathrm{L}$ annexin-FITC stain and $5 \mu \mathrm{L}$ propidium iodide (Malo et al.). The mixture was maintained in the dark at room temperature $\left(25^{\circ} \mathrm{C}\right)$ for $15 \mathrm{~min}$. Thereafter, $400 \mu \mathrm{L}$ of $1 \times$ annexin buffer was mixed to the tubes and analyzed by flow cytometry.

\subsection{Sperm plasma membrane integrity}

Hypo-osmotic swelling (HOS) assay was used to assess the sperm plasma membrane integrity. In brief, approximately 200 sperms were incubated for $30 \mathrm{~min}$ in the HOS solution and then examined under a phasecontrast microscope (Eclipse Ts2; Nikon, Minato-Ku, Tokyo, Japan) within 5-10 min. Coiled sperm tails showing swelling indicate an intact sperm plasma membrane. Acrosome integrity was examined through using fluorescein isothiocyanate-conjugated peanut agglutinin (FITC-PNA) stain (Almubarak et al. 2021, Kang et al. 2020). Briefly, smears were prepared and fixed with methanol. After washing with PBS, $30 \mu \mathrm{L}$ of FITCPNA $(100 \mu \mathrm{l} / \mathrm{ml}$ in PBS) was added to the fixed smear and incubated in humid dark place for 30 min. Stained spermatozoa $(n>200)$ were examined through an epifluorescence microscope (1000 × magnification; Eclipse Ts 2, Nikon), and categorized according to the presence or absence of fluorescence staining (i.e. acrosomeintact spermatozoa emitted intense green fluorescence on the anterior sperm).

\subsection{Mucus penetration test}

By the aid of modified synthetic oviductal fluid on flat capillary tubes $(80 \pm 0.5 \mathrm{~mm}$ long, $1.25 \pm 0.05 \mathrm{~mm}$ wide; Hilgenberg $\mathrm{GmBH}$, Stutzerbach, Germany), sperm penetration test was evaluated. After sealing one periphery of the flat capillary tube, it was filled with mucus and left to stand for $15 \mathrm{~min}$. Thereafter, the open periphery of the flat capillary tubes was immersed in a $100 \mu \mathrm{L}$ of semen samples and left horizontally at $25^{\circ} \mathrm{C}$ for $2 \mathrm{~h}$. The numbers of spermatozoa reached the marks of 1 and $3 \mathrm{~cm}$ were counted.

\subsection{Statistical Analysis}

Data were analyzed by the Statistical Package for Social Sciences (SPSS, version 24.0 software, IBM, Armonk, NY, USA). Data were expressed as the mean \pm standard error of the means (SEM). Data of motion characteristics and percentages of live sperms were analyzed with one-way analysis of variance (ANOVA) and Tukey's multiple comparison test. $\mathrm{P}<0.05$ was considered a statistical significance.

\section{Results}

\subsection{Effect of quercetin on ROS level}

ROS levels were measured by calculating the percentage of sperm stained with H2DCFDA from the total percentage of live sperm (stained negatively with PI). Control group showed increased ROS levels $(P<0.05)$ when compared with the quercetin-treated groups (Fig. 1). The oxidative stress index was $17.56 \pm 1.02,7.54 \pm$ $0.48,5.66 \pm 0.80$, and $10.41 \pm 0.69$ in the control, and the 25,50 and $100 \mu \mathrm{M}$ quercetin treatment groups, respectively. The oxidative stress index was statistically significantly different $(p<0.05)$ among the various concentrations of quercetin and the control (Fig. 1). Of the treatment groups, the $50 \mu \mathrm{M}$ quercetin group was found to have the most significantly lower ROS level, which indicates that the optimal concentration for antioxidant activity is $50 \mu \mathrm{M}$. 


\subsection{Effect of quercetin on PS translocation index (Apoptosis status)}

The apoptosis index was measured by evaluating the PS translocation. The percentage of apoptotic spermatozoa (annexin $\mathrm{V}+/ \mathrm{PI}-$ ) was calculated from the total live spermatozoa (PI-), and the data were considered as the PS translocation index. The apoptosis index values were $9.1 \pm 1.34,6.66 \pm 0.58,6.77 \pm 0.66$, and $5.38 \pm 0.86$ in the control, and the 25,50 , and $100 \mu \mathrm{M}$ quercetin treatment groups, respectively; the control group showed significantly higher values than the quercetin-treated groups. However, no differences were observed between the quercetin-treated groups (Fig. 2).

\subsection{Effect of quercetin on sperm motility and percentage of live sperm}

The motility, motion characteristics, and viability results are shown in Table 1. Post-thaw semen in samples frozen with $50 \mu \mathrm{M}$ quercetin $(51.8 \pm 2.1 \%)$ showed higher motility than control samples $(43.1 \pm 1.4 \%)(P<0.05)$. Motion characteristics showed no difference between the control and $25 \mu \mathrm{M}$ quercetin groups, while the values, except for $\mathrm{ALH}$, tended to be reduced with as quercetin concentration increased. In addition, the percentage of live sperms was increased in the samples frozen with $50 \mu \mathrm{M}$ quercetin $(46.9 \pm 0.7 \%)$ when compared with the control samples $(43.9 \pm 0.4 \%)(P<0.05)$. However, there was no difference between the control, $25 \mu \mathrm{M}(49.6 \pm 2.7)$ and $100 \mu \mathrm{M}(40.7 \pm 4.4)$ quercetin groups (Table 1$)$. The motility and viability of post-thaw sperm were significantly increased in sperms supplemented with $50 \mu \mathrm{M}$ quercetin when compared with the other groups. 
Table 1

Effects of quercetin (QRN) on the motility and motion variables of post-thaw dog spermatozoa.

\begin{tabular}{|c|c|c|c|c|c|c|c|c|c|}
\hline Groups & $\begin{array}{l}\text { Motility } \\
(\%)\end{array}$ & $\begin{array}{l}\text { Progressive } \\
\text { motility(\%) }\end{array}$ & $\begin{array}{l}\text { VCL } \\
\text { ( } \mathrm{\mu m} / \mathrm{s})\end{array}$ & $\begin{array}{l}\text { VAP } \\
(\mu \mathrm{m} / \mathrm{s})\end{array}$ & $\begin{array}{l}\text { VSL } \\
(\mu \mathrm{m} / \mathrm{s})\end{array}$ & $\begin{array}{l}\text { Straight } \\
(\%)\end{array}$ & $\begin{array}{l}\text { Linearity } \\
(\%)\end{array}$ & $\begin{array}{l}\text { ALH } \\
(\mu \mathrm{m})\end{array}$ & $\begin{array}{l}\text { Live } \\
\text { sperms } \\
(\%)\end{array}$ \\
\hline Control & $\begin{array}{l}43.1 \pm \\
1.4^{b}\end{array}$ & $22.4 \pm 1.4^{b}$ & $\begin{array}{l}70.7 \pm \\
2.3^{a}\end{array}$ & $\begin{array}{l}58.6 \pm \\
2.3^{a}\end{array}$ & $\begin{array}{l}54.2 \pm \\
2.4^{a}\end{array}$ & $\begin{array}{l}77.3 \pm \\
0.8^{a}\end{array}$ & $\begin{array}{l}61.5 \pm \\
0.8^{a}\end{array}$ & $\begin{array}{l}2.0 \\
\pm 0.0 \\
b\end{array}$ & $\begin{array}{l}43.9 \pm \\
0.4^{b}\end{array}$ \\
\hline $\begin{array}{l}25 \mu \mathrm{M} \\
\text { QRN }\end{array}$ & $\begin{array}{l}49.6 \pm \\
2.7^{a}\end{array}$ & $27.4 \pm 2.5^{a}$ & $\begin{array}{l}72.5 \pm \\
2.9^{a}\end{array}$ & $\begin{array}{l}58.9 \pm \\
2.5^{a}\end{array}$ & $\begin{array}{l}54.4 \pm \\
2.5^{a}\end{array}$ & $\begin{array}{l}75.6 \pm \\
1.6^{\mathrm{ab}}\end{array}$ & $\begin{array}{l}59.6 \pm \\
1.6^{a}\end{array}$ & $\begin{array}{l}2.1 \\
\pm 0.0 \\
b\end{array}$ & $\begin{array}{l}45.7 \pm \\
1.6^{a}\end{array}$ \\
\hline $\begin{array}{l}50 \mu \mathrm{M} \\
\text { QRN }\end{array}$ & $\begin{array}{l}51.8 \pm \\
2.1^{\mathrm{a}}\end{array}$ & $22.5 \pm 3.4^{b}$ & $\begin{array}{l}65.3 \pm \\
4.5^{a b}\end{array}$ & $\begin{array}{l}52.3 \pm \\
4.4^{b}\end{array}$ & $\begin{array}{l}47.2 \pm \\
4.5^{a b}\end{array}$ & $\begin{array}{l}70.3 \pm \\
1.9^{b}\end{array}$ & $\begin{array}{l}52.9 \pm \\
2.7^{b}\end{array}$ & $\begin{array}{l}2.0 \\
\pm 0.1 \\
b\end{array}$ & $\begin{array}{l}46.9^{ \pm} \\
0.7^{a}\end{array}$ \\
\hline $\begin{array}{l}100 \\
\mu M \\
\text { QRN }\end{array}$ & $\begin{array}{l}40.7 \pm \\
4.4^{b}\end{array}$ & $19.8 \pm 2.6^{b}$ & $\begin{array}{l}63.1 \pm \\
6.8^{b}\end{array}$ & $\begin{array}{l}50.0^{ \pm \pm} \\
2.9^{b}\end{array}$ & $\begin{array}{l}45.2 \pm \\
3.2^{b}\end{array}$ & $\begin{array}{l}72.3 \pm \\
2.4^{b}\end{array}$ & $\begin{array}{l}51.3 \pm \\
2.7^{b}\end{array}$ & $\begin{array}{l}2.3 \\
\pm 0.1 \\
a\end{array}$ & $\begin{array}{l}43.6 \pm \\
0.9 \mathrm{ab}\end{array}$ \\
\hline
\end{tabular}

${ }^{a-b}$ Within the same column, values with different lowercase superscripts differ significantly $(p<0.05, n=$ 7).

ALH, amplitude of lateral head displacement; VAP, average path velocity; VCL, curvilinear velocity; VSL, straight-line velocity.

\subsection{Effect of quercetin on sperm plasma membrane integrity}

HOS test showed a significant increase in plasma membrane integrity of the quercetin-supplemented groups compared to the control group ( $54.0 \pm 0.6 \%$ vs. $46.6 \pm 0.7 \%$, respectively). However, there was a significant decrease in the membrane integrity of sperm samples supplemented with $100 \mu \mathrm{M}$ quercetin $(45.2 \pm 0.6 \%)$ (Table 2). FITC-PNA staining showed that quercetin supplementation did not effectively protect the acrosomal integrity of the cryopreserved dog sperm, as no statistically significant differences were found between the quercetin-supplemented sperm samples and the control samples. 
Table 2

Effects of quercetin (QRN) supplementation on plasma membrane integrity, acrosome, and mitochondria of post-thaw dog spermatozoa.

\begin{tabular}{|c|c|c|c|c|}
\hline Groups & HOS (\%) & $\begin{array}{l}\text { Mitochondrial activity } \\
(\%)\end{array}$ & $\begin{array}{l}\text { Acrosome integrity } \\
(\%)\end{array}$ & $\begin{array}{l}\text { Chromatin integrity } \\
(\%)\end{array}$ \\
\hline Control & $46.6 \pm 0.7^{b}$ & $44.4 \pm 0.5^{b}$ & $61.6 \pm 3.2$ & $58.9 \pm 0.9 b$ \\
\hline $25 \mu \mathrm{M}$ QRN & $\begin{array}{l}49.2 \pm 0.6 \\
a b\end{array}$ & $47.1 \pm 0.7^{a b}$ & $53.7 \pm 2.7$ & $61.6 \pm 0.8^{a b}$ \\
\hline $50 \mu \mathrm{M}$ QRN & $54.0 \pm 0.6^{a}$ & $49.5 \pm 1.8^{a}$ & $60.7 \pm 4.4$ & $64.3 \pm 0.7^{a}$ \\
\hline $\begin{array}{l}100 \mu \mathrm{M} \\
\text { QRN }\end{array}$ & $45.2 \pm 0.6^{b}$ & $45.5 \pm 1.6^{b}$ & $54.9 \pm 1.7$ & $57.1 \pm 0.5^{b}$ \\
\hline
\end{tabular}

Results showed that $50 \mu \mathrm{M}$ quercetin-supplemented post-thaw sperm penetrated the modified synthetic oviductal fluid more effectively than control group (69.2 \pm 1.3 vs. $51.5 \pm 1.9$ at $1 \mathrm{~cm}$ and $15.1 \pm 1.6$ vs. $27.0 \pm$ 1.1 at $3 \mathrm{~cm}$ ), respectively. The sperm counts for quercetin-supplemented sperm samples were significantly higher at both the 1- and 3-cm marks than those for the control sperm (Table 3). The motility-promoting effects of 25 and $100 \mu \mathrm{M}$ quercetin were less than those of $50 \mu \mathrm{M}$ quercetin at both 1 and $3 \mathrm{~cm}$; however, the effect of $100 \mu \mathrm{M}$ was relatively higher than that of $25 \mu \mathrm{M}$ quercetin at $1 \mathrm{~cm}$ (Table 3).

Table 3

Effects of quercetin (QRN) supplementation on the mucus penetration ability of post-thaw dog spermatozoa.

\begin{tabular}{|lll|}
\hline Group & \multicolumn{2}{l|}{ Numbers of spermatozoa penetrating the mucus } \\
\cline { 2 - 3 } & $\mathbf{1} \mathbf{~ c m}$ & $3 \mathrm{~cm}$ \\
\hline Control & $51.5 \pm 1.9^{\mathrm{b}}$ & $15.1 \pm 1.6^{\mathrm{b}}$ \\
\hline $25 \mu \mathrm{M}$ QRN & $59.0 \pm 0.8^{\mathrm{ab}}$ & $20.2 \pm 1.3^{\mathrm{ab}}$ \\
\hline $50 \mu \mathrm{M}$ QRN & $69.2 \pm 1.3^{\mathrm{a}}$ & $27.0 \pm 1.1^{\mathrm{a}}$ \\
\hline $100 \mu \mathrm{M}$ QRN & $61.7 \pm 1.8^{\mathrm{ab}}$ & $19.2 \pm 0.7^{\mathrm{ab}}$ \\
\hline
\end{tabular}

a-b Within the same column, values with different superscripts differ significantly $(p<0.05, n=7)$.

\section{Discussion}

Cryopreservation is a crucial tool for preserving of spermatozoa and the genetic merits of valuable species for a long time. However, cryodamage due to freezing and thawing compromises the fertility of sperm post-thaw. Cryodamage at the molecular level due to freezing and thawing is also a concern during long-term preservation of dog sperm (England 1993, Farstad 2009, Vieira et al. 2018). Cryodamage can be caused 
through the generation of ROS in sperm. However, supplementing antioxidants during sperm freezing to reverse the effect of ROS has been used to ameliorate these adverse effects (Majzoub \&Agarwal 2020).

Herein, the observed reduction in oxidative stress by the application of quercetin in dog sperm coincides with the results found in the rats, Red Jungle fowl and the roosters where supplementation with quercetin reduced oxidative stress (Najafi et al. 2020, Rakha et al. 2020, Yelumalai et al. 2019). The mechanism employed by quercetin to ameliorate oxidative stress in post-thaw sperm is thought to occur via an increase in the sperm total antioxidant capacity and the amelioration of lipid peroxidation (Papas et al. 2019). Quercetin has also caused improvements in advanced DNA integrity, owing to reduced ROS levels, as reported in bulls (Avdatek et al. 2018), which could have contributed to fertility. The lipid peroxidation reduction ability of quercetin (Yang et al. 2020) is believed to contribute to oxidative stress in post-thawed sperm. Accordingly, we anticipate that further sperm quality criteria and the in vitro fertility test could be conducted to further validate the effectiveness of sperm. Evaluation of post-thaw sperm revealed significantly improved viability in the quercetin-supplemented sperm samples compared to control samples. Moreover, higher percentages of sperm with intact membranes were observed in the quercetin-supplemented sperm samples than in the control samples. The greater membrane integrity of quercetin-supplemented sperm is an indicator of preserved sperm structure and ultimately the enhanced survival rate of sperm (Ismail et al. 2020).

Sperm are very sensitive to oxidative stress owing to their limited oxidative defense mechanisms (Alahmar 2019, Sabeti et al. 2016). The sensitivity to oxidative stress is further amplified by the dilution of semen antioxidantive enzymes during semen dilution process and excessive ROS generation during post-thaw (Bansal \&Bilaspuri 2010). The ROS produced during cryopreservation lead to a decrease in sperm motility, viability, acrosome membrane integrity, and fertilization capacity (Baumber et al. 2000, Sariözkan et al. 2009). Furthermore, ROS generation during cryopreservation triggers the apoptosis of spermatozoa, eventually leading to sperm loss of function or death (Said et al. 2004, Said et al. 2010). Moreover, under these stress conditions, the mitochondrial membrane potential decreases and apoptosis is enhanced by ROS generation (Redza-Dutordoir \&Averill-Bates 2016). Quercetin displayed potent antioxidative properties owing to its preventative effects on ROS formation. It antagonizes the enzymatic (nicotinamide adenine dinucleotide phosphate (NADPH) oxidase and nicotinamide adenine dinucleotide (NADH)-dependent oxidoreductase) and non-enzymatic systems involved the ROS formation (Walczak-Jedrzejowska et al. 2013).

The reduced apoptotic index due to the application of quercetin is attributed to its ability to inhibit lipopolysaccharide-induced mRNA expression of tumor necrosis factor a (TNF-a) and interleukin (IL-1a) (Bureau et al. 2008). This effect of quercetin could be an additional mechanism for the reduced apoptosis and integrity of the sperm; however, further studies are needed to confirm this. Our results coincide with the recent results of Kawasaki et al. (Kawasaki et al. 2020) who observed that the skim milk-based extender supplemented with $5 \mu \mathrm{g} / \mathrm{ml}$ quercetin and $0.1 \%$ dimethyl sulfoxide improved the motility and fertility of cryopreserved dog spermatozoa. Similarly, the application of quercetin in stallion sperm cryopreservation caused improved post-thaw sperm quality, such as protecting DNA fragmentation, motility, and zona binding ability (Gibb et al. 2013, Seifi-Jamadi et al. 2016).

This study revealed that supplementation of a freezing extender with $50 \mu \mathrm{M}$ quercetin improved the motility and survival of frozen-thawed dog sperm. This finding aligns with that of previous studies on the effect of 
quercetin on reducing oxidative stress in humans $(15 \mu \mathrm{g} / \mathrm{ml})$ (Zribi et al. 2012) and stallions $(45 \mu \mathrm{g} / \mathrm{ml})$ (Zribi et al. 2012). This effect of quercetin might be due to its free radical scavenging capacity and its effect on lipid peroxidation (Mazzi et al. 2012) which could reduce the level of ROS and subsequently decrease the number of apoptotic spermatozoa. However, quercetin is a versatile flavonoid; after displaying its antioxidant effect, it changes to a toxic product that might affect sperm quality (Mazzi et al. 2012) as observed in the $100 \mu \mathrm{M}$ quercetin group in this study. Therefore, determining the optimum concentration and cryopreservation conditions should be performed to enable the effective application of antioxidants in cryopreservation. In this study, quercetin supplementation improved post-thaw motility as well as the proportion of total and progressively motile dog sperm, which reflects improved fertility. The mucus penetration test also confirmed the improved motility of the quercetin-supplemented sperm sample. The effects of quercetin supplementation on canine sperm cryopreservation are summarized in Fig. 3.

\section{Conclusions}

The quercetin-supplemented freezing extender had a significant effect in ameliorating cryo-induced oxidative stress and apoptosis, and protected the key fertility parameters of post-thaw dog sperm, such as mucus penetration, membrane integrity, and livability. Therefore, we recommended the addition of quercetin as a vital cryoprotectant supplement to maintain the survival and motility of post-thaw sperm (Collins \&Ryan 2011, Henkel et al. 2004). Based on our analysis, the optimum concentration of quercetin for protecting post-thaw dog sperm against oxidative stress-induced damage is $50 \mu \mathrm{M}$.

\section{Declarations}

Author Contributions: Conceptualization, S.B., A.Y.Q., and J.C.; methodology, S.B., A.Y.Q., B.M.T., X.F., G.S., A.H.T.N., I.J.Y., and J.C.; Investigation, S.B., B.M.T, and A.Y.Q.; data curation, S.B., B.M.T, and A.Y.Q.; writingoriginal draft preparation, S.B., B.M.T. and A.H.T.N.; writing-review and editing, S.B., B.M.T., A.Y.Q., I.J.Y., I.M.S., and J.C.; supervision, J.C.; project administration, J.C.; funding acquisition, J.C.

Funding: This research was funded by a National Research Foundation of Korea (NRF) grant funded by the Korean government (MSIT) (grant number. 2021R1A2C2009294).

\section{Institutional Review Board Statement: N/A}

Informed Consent Statement: N/A

Data Availability Statement: The data used to support the findings of this study are included within the article.

Acknowledgments: The authors would like to express their gratitude to Prof. Chul Park at Jeonbuk National University and Kyu-Pil Lee \& Je-Won Ko at Chungnam National University for permitting the use of their laboratory facilities.

Conflicts of Interest: The authors declare no conflict of interest.

\section{References}


1. Ahmed W, Lingner J (2020): PRDX1 Counteracts Catastrophic Telomeric Cleavage Events That Are Triggered by DNA Repair Activities Post Oxidative Damage. Cell Rep 33, 108347

2. Alahmar AT (2019): Role of Oxidative Stress in Male Infertility: An Updated Review. J Hum Reprod Sci 12, 4-18

3. Almubarak AM, Kim W, Abdelbagi NH, Balla SE, Yu I-J, Jeon Y (2021): Washing solution and centrifugation affect kinematics of cryopreserved boar semen. J Anim Reprod Biotechnol 36, 65-75

4. Alvarez JG, Storey BT (1989): Role of glutathione peroxidase in protecting mammalian spermatozoa from loss of motility caused by spontaneous lipid peroxidation. Gamete Res 23, 77-90

5. Ashida H, Fukuda I, Yamashita T, Kanazawa K (2000): Flavones and flavonols at dietary levels inhibit a transformation of aryl hydrocarbon receptor induced by dioxin. FEBS Lett 476, 213-7

6. Avdatek F, Yeni D, İnanç ME, Çil B, Tuncer BP, Türkmen R, Taşdemir U (2018): Supplementation of quercetin for advanced DNA integrity in bull semen cryopreservation. Andrologia

7. Azadi L, Tavalaee M, Deemeh MR, Arbabian M, Nasr-Esfahani MH (2017): Effects of Tempol and Quercetin on Human Sperm Function after Cryopreservation. Cryo letters 38, 29-36

8. Bali EB, Ergin V, Rackova L, Bayraktar O, Küçükboyaci N, Karasu Ç (2014): Olive leaf extracts protect cardiomyocytes against 4-hydroxynonenal-induced toxicity in vitro: comparison with oleuropein, hydroxytyrosol, and quercetin. Planta Med 80, 984-92

9. Bang S, Qamar AY, Tanga BM, Fang X, Cho J (2021): Resveratrol supplementation into extender protects against cryodamage in dog post-thaw sperm. J Vet Med Sci

10. Bansal AK, Bilaspuri GS (2010): Impacts of Oxidative Stress and Antioxidants on Semen Functions. Veterinary Medicine International 2010, 686137

11. Barciszewski J, Siboska G, Clark BF, Rattan SI (2000): Cytokinin formation by oxidative metabolism. Journal of plant physiology 157, 587-588

12. Baumber J, Ball BA, Gravance CG, Medina V, Davies-Morel MC (2000): The effect of reactive oxygen species on equine sperm motility, viability, acrosomal integrity, mitochondrial membrane potential, and membrane lipid peroxidation. J Androl 21, 895-902

13. Bureau G, Longpré F, Martinoli MG (2008): Resveratrol and quercetin, two natural polyphenols, reduce apoptotic neuronal cell death induced by neuroinflammation. J Neurosci Res 86, 403-10

14. Carrasco-Pozo C, Mizgier ML, Speisky H, Gotteland M (2012): Differential protective effects of quercetin, resveratrol, rutin and epigallocatechin gallate against mitochondrial dysfunction induced by indomethacin in Caco-2 cells. Chem Biol Interact 195, 199-205

15. Collins MM, Ryan AK (2011): Manipulating claudin expression in avian embryos. Methods Mol Biol 762 , 195-212

16. Diao R, Gan H, Tian F, Cai X, Zhen W, Song X, Duan YG (2019): In vitro antioxidation effect of Quercetin on sperm function from the infertile patients with leukocytospermia. American Journal of Reproductive Immunology 82

17. El-Said KS, Ali EM, Kanehira K, Taniguchi A (2014): Molecular mechanism of DNA damage induced by titanium dioxide nanoparticles in toll-like receptor 3 or 4 expressing human hepatocarcinoma cell lines. $J$ Nanobiotechnology 12, 48 
18. England GC (1993): Cryopreservation of dog semen: a review. J Reprod Fertil Suppl 47, 243-55

19. Ezzati M, Yousefi B, Velaei K, Safa A (2020): A review on anti-cancer properties of Quercetin in breast cancer. Life Sci 248, 117463

20. Farstad W (2009): Cryopreservation of canine semen - new challenges. Reprod Domest Anim 44 Suppl 2 , 336-41

21. Formica JV, Regelson W (1995): Review of the biology of quercetin and related bioflavonoids. Food and Chemical Toxicology 33, 1061-1080

22. Fraser L, Strzeżek J, Kordan W (2011): Effect of freezing on sperm nuclear DNA. Reproduction in Domestic Animals 46, 14-17

23. Fukuda I, Ashida H (2008): Suppressive Effects of Flavonoids on Activation of the Aryl Hydrocarbon Receptor Induced by Dioxins, Functional Food and Health. ACS Symposium Series. American Chemical Society, pp. 369-374

24. Gibb Z, Butler TJ, Morris LH, Maxwell WM, Grupen CG (2013): Quercetin improves the postthaw characteristics of cryopreserved sex-sorted and nonsorted stallion sperm. Theriogenology 79, 1001-9

25. Guthrie HD, Welch GR (2010): Using fluorescence-activated flow cytometry to determine reactive oxygen species formation and membrane lipid peroxidation in viable boar spermatozoa. Methods Mol Biol 594, 163-71

26. Han X, Xu T, Fang Q, Zhang H, Yue L, Hu G, Sun L (2021): Quercetin hinders microglial activation to alleviate neurotoxicity via the interplay between NLRP3 inflammasome and mitophagy. Redox Biol 44, 102010

27. Henkel R, Hajimohammad M, Stalf T, Hoogendijk C, Mehnert C, Menkveld R, Gips H, Schill WB, Kruger TF (2004): Influence of deoxyribonucleic acid damage on fertilization and pregnancy. Fertil Steril 81, 965-72

28. Hussein MMA, Ali HA, Saadeldin IM, Ahmed MM (2016): Querectin Alleviates Zinc Oxide Nanoreprotoxicity in Male Albino Rats. Journal of Biochemical and Molecular Toxicology 30, 489-496

29. Ismail AA, Abdel-Khalek A-KE, Khalil WA, Yousif Al, Saadeldin IM, Abomughaid MM, El-Harairy MA (2020): Effects of mint, thyme, and curcumin extract nanoformulations on the sperm quality, apoptosis, chromatin decondensation, enzyme activity, and oxidative status of cryopreserved goat semen. Cryobiology 97, 144152

30. Iwasaki A, Gagnon C (1992): Formation of reactive oxygen species in spermatozoa of infertile patients. Fertil Steril 57, 409-16

31. Kang J-T, Moon JH, Choi J-Y, Park SJ, Kim SJ, Saadeldin IM, Lee BC (2016): Effect of Antioxidant Flavonoids (Quercetin and Taxifolin) on $<i>$ In vitro $</ i>$ Maturation of Porcine Oocytes. Asian-Australasian Journal of Animal Sciences 29, 352-358

32. Kang S-S, Kim U-H, Lee M-S, Lee S-D, Cho S-R (2020): Spermatozoa motility, viability, acrosome integrity, mitochondrial membrane potential and plasma membrane integrity in $0.25 \mathrm{~mL}$ and $0.5 \mathrm{~mL}$ straw after frozen-thawing in Hanwoo bull. J Anim Reprod Biotechnol 35, 307-314

33. Kashou AH, Sharma R, Agarwal A (2013): Assessment of oxidative stress in sperm and semen, Spermatogenesis. Springer, pp. 351-361 
34. Kawasaki Y, Sakurai D, Yoshihara T, Tsuchida M, Harakawa S, Suzuki H (2020): Effect of quercetin on the motility of cryopreserved canine spermatozoa. Cryobiology 96, 50-54

35. Kim TY, Leem E, Lee JM, Kim SR (2020): Control of Reactive Oxygen Species for the Prevention of Parkinson's Disease: The Possible Application of Flavonoids. Antioxidants (Basel) 9

36. Liu X, Xu Y, Liu F, Pan Y, Miao L, Zhu Q, Tan S (2021): The Feasibility of Antioxidants Avoiding Oxidative Damages from Reactive Oxygen Species in Cryopreservation. Front Chem 9, 648684

37. Majzoub A, Agarwal A (2020): Antioxidants in Sperm Cryopreservation. In: Parekattil SJ, Esteves SC, Agarwal A (Editors), Male Infertility: Contemporary Clinical Approaches, Andrology, ART and Antioxidants. Springer International Publishing, Cham, pp. 671-678

38. Malo C, Gil L, Gonzalez N, Martínez F, Cano R, de Blas I, Espinosa E (2010): Anti-oxidant supplementation improves boar sperm characteristics and fertility after cryopreservation: Comparison between cysteine and rosemary (Rosmarinus officinalis). Cryobiology 61, 142-147

39. Martin G, Sabido O, Durand P, Levy R (2005): Phosphatidylserine externalization in human sperm induced by calcium ionophore A23187: relationship with apoptosis, membrane scrambling and the acrosome reaction. Hum Reprod 20, 3459-68

40. Mazzi L, Geminiani M, Collodel G, lacoponi F, Martini S, Bonechi C, Rossi C, Moretti E (2012): QUERCETIN AND RUTIN: EFFECTS OF TWO FLAVONOIDS ON INDUCED OXIDATIVE STRESS IN HUMAN EJACULATED SPERM. Journal of the Siena Academy of Sciences 3, 22-26

41. Moodi Z, Bagherzade G, Peters J (2021): Quercetin as a Precursor for the Synthesis of Novel Nanoscale $\mathrm{Cu}$ (II) Complex as a Catalyst for Alcohol Oxidation with High Antibacterial Activity. Bioinorg Chem Appl 2021,8818452

42. Moon YJ, Morris ME (2007): Pharmacokinetics and bioavailability of the bioflavonoid biochanin A: effects of quercetin and EGCG on biochanin A disposition in rats. Mol Pharm 4, 865-72

43. Najafi A, Kia HD, Mehdipour M, Hamishehkar H, Alvarez-Rodriguez M (2020): Effect of quercetin loaded liposomes or nanostructured lipid carrier (NLC) on post-thawed sperm quality and fertility of rooster sperm. Theriogenology 152, 122-128

44. Papas M, Catalán J, Fernandez-Fuertes B, Arroyo L, Bassols A, Miró J, Yeste M (2019): Specific Activity of Superoxide Dismutase in Stallion Seminal Plasma Is Related to Sperm Cryotolerance. Antioxidants (Basel) 8, 539

45. Qamar AY, Fang X, Bang S, Kim MJ, Cho J (2020): Effects of kinetin supplementation on the post-thaw motility, viability, and structural integrity of dog sperm. Cryobiology 95, 90-96

46. Rakha BA, Qurrat UI A, Ansari MS, Akhter S, Akhter A, Awan MA, Santiago-Moreno J (2020): Effect of Quercetin on Oxidative Stress, Mitochondrial Activity, and Quality of Indian Red Jungle Fowl (Gallus gallus murghi) Sperm. Biopreserv Biobank 18, 311-320

47. Redza-Dutordoir M, Averill-Bates DA (2016): Activation of apoptosis signalling pathways by reactive oxygen species. Biochim Biophys Acta 1863, 2977-2992

48. Ricci G, Perticarari S, Fragonas E, Giolo E, Canova S, Pozzobon C, Guaschino S, Presani G (2002): Apoptosis in human sperm: its correlation with semen quality and the presence of leukocytes. Hum Reprod 17, 2665-72 
49. Russo M, Spagnuolo C, Tedesco I, Bilotto S, Russo GL (2012): The flavonoid quercetin in disease prevention and therapy: facts and fancies. Biochem Pharmacol 83, 6-15

50. Sabeti P, Pourmasumi S, Rahiminia T, Akyash F, Talebi AR (2016): Etiologies of sperm oxidative stress. Int J Reprod Biomed 14, 231-40

51. Said TM, Agarwal A, Sharma RK, Mascha E, Sikka SC, Thomas AJ, Jr. (2004): Human sperm superoxide anion generation and correlation with semen quality in patients with male infertility. Fertil Steril 82, 871-7

52. Said TM, Gaglani A, Agarwal A (2010): Implication of apoptosis in sperm cryoinjury. Reprod Biomed Online 21, 456-62

53. Sariözkan S, Bucak MN, Tuncer PB, Ulutaş PA, Bilgen A (2009): The influence of cysteine and taurine on microscopic-oxidative stress parameters and fertilizing ability of bull semen following cryopreservation. Cryobiology $58,134-8$

54. Schieber M, Chandel NS (2014): ROS function in redox signaling and oxidative stress. Curr Biol 24, R45362

55. Seifi-Jamadi A, Kohram H, Zare Shahneh A, Ansari M, Macías-García B (2016): Quercetin Ameliorate Motility in Frozen-Thawed Turkmen Stallions Sperm. Journal of Equine Veterinary Science 45, 73-77

56. Setyawan EMN, Kim MJ, Oh HJ, Kim GA, Jo YK, Lee SH, Choi YB, Lee BC (2016): Spermine reduces reactive oxygen species levels and decreases cryocapacitation in canine sperm cryopreservation. Biochem Biophys Res Commun 479, 927-932

57. Shiratsuchi A, Umeda M, Ohba Y, Nakanishi Y (1997): Recognition of phosphatidylserine on the surface of apoptotic spermatogenic cells and subsequent phagocytosis by Sertoli cells of the rat. J Biol Chem 272, 2354-8

58. Snezhkina AV, Kudryavtseva AV, Kardymon OL, Savvateeva MV, Melnikova NV, Krasnov GS, Dmitriev AA (2019): ROS Generation and Antioxidant Defense Systems in Normal and Malignant Cells. Oxid Med Cell Longev 2019, 6175804

59. Su L-J, Zhang J-H, Gomez H, Murugan R, Hong X, Xu D, Jiang F, Peng Z-Y (2019): Reactive Oxygen Species-Induced Lipid Peroxidation in Apoptosis, Autophagy, and Ferroptosis. Oxid Med Cell Longev 2019, 5080843-5080843

60. Tanga BM, Qamar AY, Raza S, Bang S, Fang X, Yoon K, Cho J (2021): Semen evaluation: methodological advancements in sperm quality-specific fertility assessment - A review. Anim Biosci 34, 1253-1270

61. Tvrdá E, Kováčik A, Tušimová E, Paál D, Mackovich A, Alimov J, Lukáč N (2016): Antioxidant efficiency of lycopene on oxidative stress - induced damage in bovine spermatozoa. J Anim Sci Biotechnol 7, 50

62. Vieira NMG, Losano JDA, Angrimani DSR, Kawai GKV, Bicudo LC, Rui BR, da Silva B, Assumpção M, Nichi M (2018): Induced sperm oxidative stress in dogs: Susceptibility against different reactive oxygen species and protective role of seminal plasma. Theriogenology 108, 39-45

63. Walczak-Jedrzejowska R, Wolski JK, Slowikowska-Hilczer J (2013): The role of oxidative stress and antioxidants in male fertility. Cent European J Urol 66, 60-7

64. Yang D, Wang T, Long M, Li P (2020): Quercetin: Its Main Pharmacological Activity and Potential Application in Clinical Medicine. Oxid Med Cell Longev 2020, 8825387 
65. Yelumalai S, Giribabu N, Karim K, Omar SZ, Salleh NB (2019): In vivo administration of quercetin ameliorates sperm oxidative stress, inflammation, preserves sperm morphology and functions in streptozotocin-nicotinamide induced adult male diabetic rats. Archives of medical science : AMS 15, 240249

66. Yoshimoto T, Nakamura S, Yamauchi S, Muto N, Nakada T, Ashizawa K, Tatemoto H (2008): Improvement of the post-thaw qualities of Okinawan native pig spermatozoa frozen in an extender supplemented with ascorbic acid 2-0-alpha-glucoside. Cryobiology 57, 30-6

67. Zribi N, Chakroun NF, Ben Abdallah F, Elleuch H, Sellami A, Gargouri J, Rebai T, Fakhfakh F, Keskes LA (2012): Effect of freezing-thawing process and quercetin on human sperm survival and DNA integrity. Cryobiology 65, 326-31

\section{Figures}

(a) $404 \mathrm{R} 1 \mathrm{QRN}$ con cr Gate: (P1 in all)

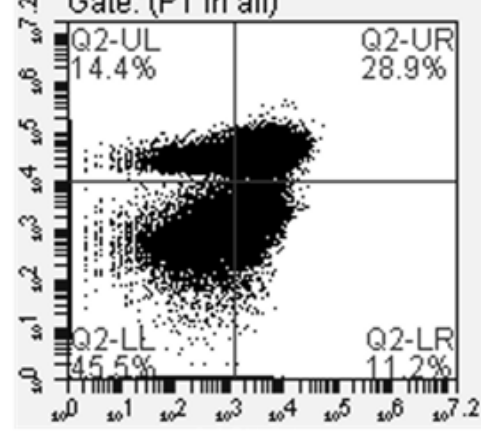

(c)A10 R1 QRN 50

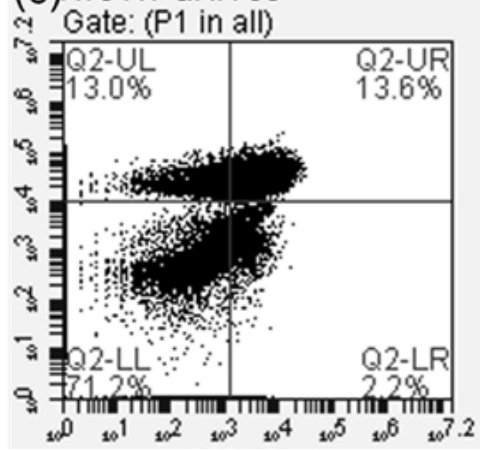

(b)B05 R2 QRN 25

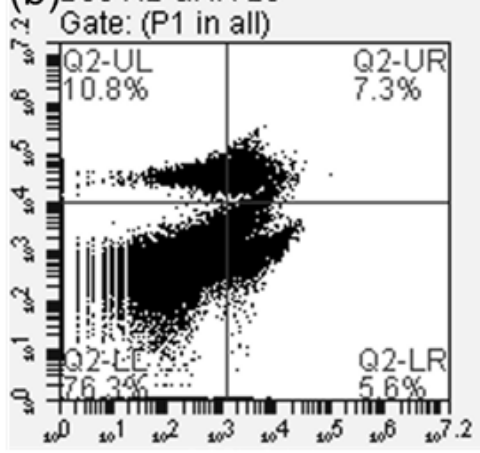

(d)C01 R2 QRN 100

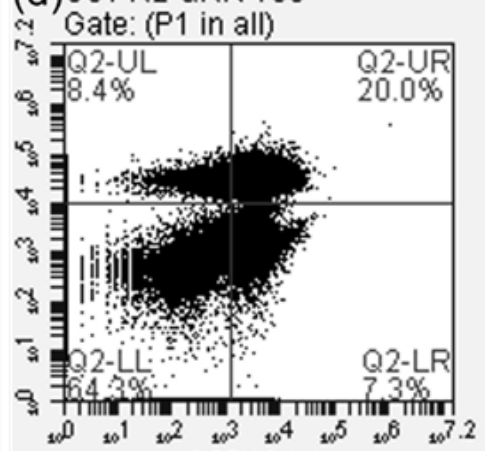

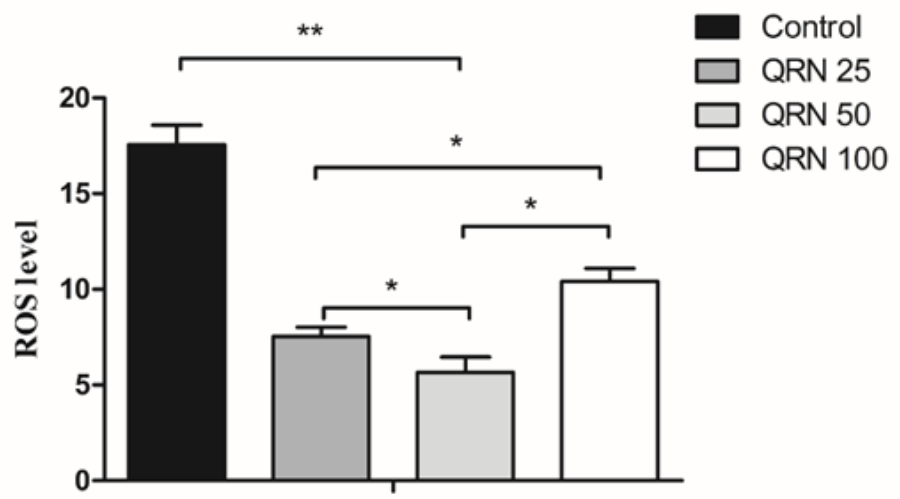

Figure 1

Effects of quercetin on ROS level in post-thaw dog spermatozoa. (a) control, (b) quercetin (QRN) 25, (c) QRN 50, (d) QRN 100. (a)-(d) are the results of DCFDA/PI staining and ROS analysis by flow cytometry. The bar graph is the result of comparing the ROS index value using the flow cytometry result. * and ** indicate that the differences between the groups are different at $\mathrm{P}<0.05$ and $\mathrm{P}<0.01$, respectively. 
(a)A08 R5 coontrol

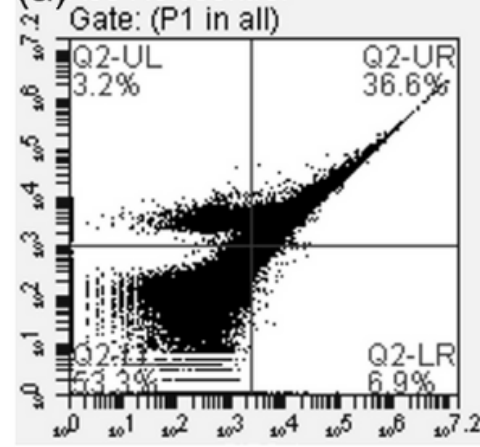

(c) B05 R2 QRN 50

G Gate: ( $P 1$ in all)

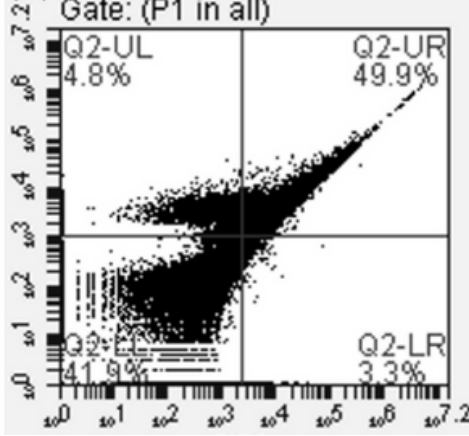

(b)B01 R4 QRN 25

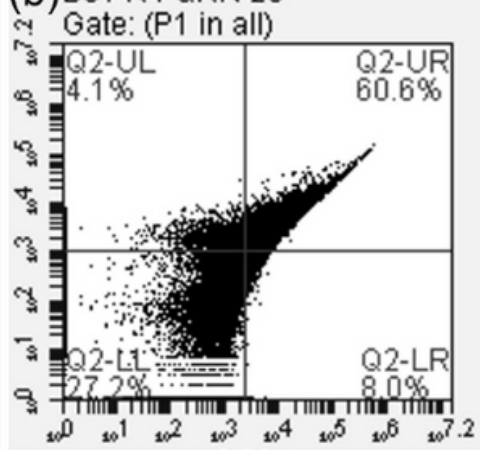

(d)B10R1 QRN 100

G Gate: (P1 in all)

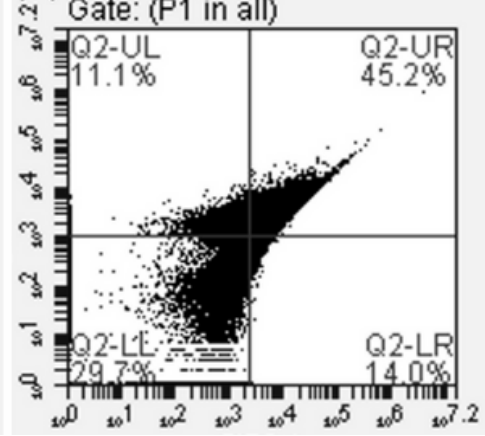

$\frac{\frac{6}{3}}{\frac{2}{2}}$

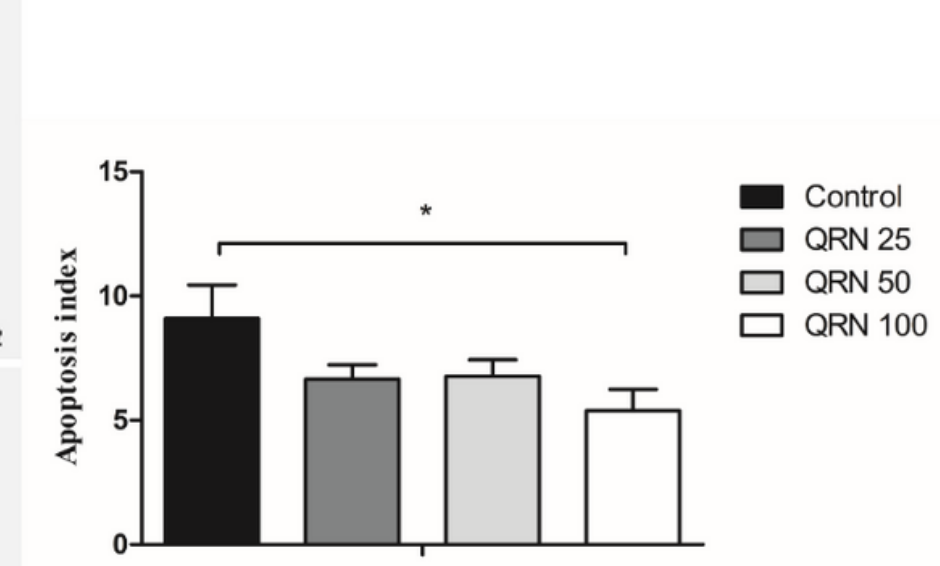

\section{Figure 2}

Impacts of quercetin on the apoptosis of post-thaw dog sperm. (a) control, (b) quercetin (QRN) 25, (c) QRN 50, (d) QRN 100. (a)-(d) are the results of Annexin V-FITC/PI staining and analysis by flow cy-tometry. * that the differences between the groups are significantly different at $\mathrm{P}<0.05$.

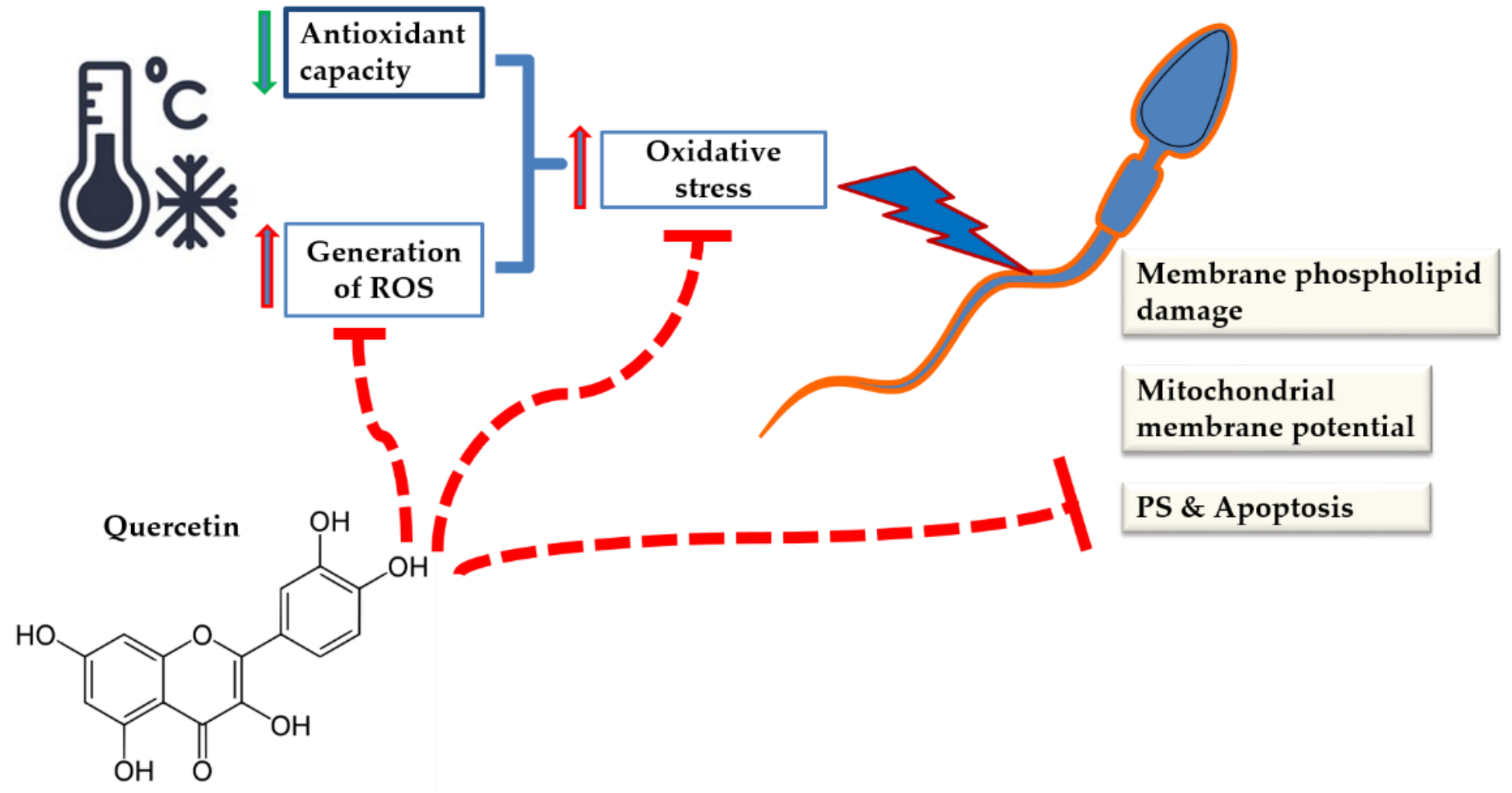

Figure 3 
The proposed beneficial effects of supplementing quercetin during the dog sperm freezing-thawing process. Quercetin ameliorates reactive oxygen species (ROS) generation and increases the antioxidant capacity, thereby reducing the oxidative stress impacts on the sperms, such as phospholipid damage, mitochondrial membrane potential, and phosphatidylserine (PS) translocation, which are associated with apoptosis. Dashed line indicates suppression of the effects. 